\title{
Corporate Values in Global Supply Chains
}

\author{
Cosetta Pepe*
}

\begin{abstract}
The problem of finding a balance between the economic, social, and environmental values of human development is now at the heart of the debate that involves men of culture, men of faith, economists and politicians, who are working together to tackle the problems of globalisation.

Chains are part of a gradual globalisation, with growing interdependence between the various manufacturing organisations and a convergence of different elements that creates development, but also negative effects such as environmental degradation and serious social imbalance.

In the corporate culture, with the evolution of marketing, the act of purchasing is a sum of ethical and aesthetic values. In this sense, global companies' supply must contain a 'synthesis' of consumers' expectations.
\end{abstract}

Keywords: Corporate Economics; Global Supply Chains; Global Markets; Corporate Values; Social and Economic Values; Ethical and Aesthetical Values

\section{Corporate Economics and Global Supply Chains}

Europe, its culture and the positive forces that animate it, are immediately and naturally exposed to other realities and other cultures, and they reveal a sense of a broad and highly diverse universe, but one that is also interdependent and citizen of a single place, which tackles the contradictions between 'society, environment and economics', trying to make compatible the goals of economic entities and those of society that the ample gamut of market economy has now extended to the whole of humanity.

The problem is tackled primarily by considering companies and their relations with consumers, other companies and the relevant environments-markets. Attention is focused on the fact that they belong to a chain, in other words to a collection of entities that together are responsible for complete manufacturing, distribution and consumption cycles, with principal roles - for manufacturers, distributors and consumers - and secondary roles, for logistics companies, banks,

*Full Professor of Management, University of Rome-Tor Vergata (cosetta.pepe@ uniroma2.it) 
insurance companies and all the other companies that sustain global development processes.

Today these chains are part of a gradual globalisation, with growing interdependence between the various manufacturing organisations and a convergence of different elements that creates development, with stimuli and opportunities for companies, but also contradictions and negative effects such as environmental degradation and serious social imbalance, which introduce issues such as that of just distribution, working conditions, individual freedom and, more generally, values to believe in. This prompts the search for principles and rules that can shed new light on economic thought that must also become political thought: i.e. winning back the comprehensive identity - of political economics - that it originally expressed.

\section{The Debate about Corporate Social and Economic Values}

The importance of 'good conduct' in economic and commercial activities, and the need for economic entities to operate in a context of widespread consensus were already the subject of analysis by early economists, although it later attenuated in consideration of the natural balances of the market which could justify a profit-based logic in individual operators.

But a logic that is founded on means (money) and not ends, can transform trade into a conflictual, occasionally even destabilising, relationship: "the mediation of the group, of society and of politics proves necessary... Economic exchange must be re-introduced to the sphere of the common good as a central element of social relationships' (Latouche, 2005).

The problem of finding a balance between the economic, social, and environmental values of human development is now at the heart of the debate that involves men of culture, men of faith, economists and politicians, who are working together to tackle the problems of globalisation. At the centre is a reflection of the responsibilities of politics and economics that is related to the imbalance of the world's social and economic order, putting in danger the ultimate goal for a civil society which is to guarantee an acceptable human condition that may be 'shared', starting from the common membership of a network of international relationship that is central to our age.

We do not meditate on ideal models but to guarantee dignity in life. The problem of justice becomes first and foremost a problem of limits (setting a limit to the degradation of the environment, unfair working conditions, and the economic divergence between people and countries).

The change necessary is above all cultural. If, in the traditional culture of manufacturing and consumption, attention was concentrated on the collocation efficiency/effectiveness and the quality/convenient ratio, what is now emerging in the new culture of businesses and consumers is a 'system of values'.

In fact, in the corporate culture, with the evolution of marketing, the act of purchasing is no longer the simple exchange of money for goods, but is becoming the expression of complex human behaviour, and as such full of sensations, sentiments, emotions, actions and thoughts corresponding to a sum of ethical and aesthetic values which has been enriched and customised in advanced markets. 
In this sense, companies' supply must contain a 'synthesis' of consumers' expectations, if possible solving any conflicts inside their conscience: some opt for clear choices and extreme consistency with the moral values professed, but most people - very humanly - aspire to overall satisfaction that is ethical and aesthetic, which demands compromise and may come from a sum of elements that have been made compatible and well balanced.

\section{The Demand for Ethical and Aesthetical Values and the Response from Companies}

By studying the consumer's behaviour, companies have understood that trade can become a means of expresses choices that are not only addressed to the purchase of products, but also strive to share the values that these convey. The complexity of the system in which they live, and the need for gratification, the aspirations, fears and uncertainties this demands are reflected in the behaviour of consumers in advanced countries.

Faced with the need to grasp the changes in consumers' behaviour and to identify the most suitable way to respond, companies propose two attitudes that are already well-known in literature: active behaviour and reactive behaviour. In fact, change may come either from a better perception of the complexity of the relationship between company and environment and a capacity to tackle it better; or from a reaction that derives from the need to come to terms with the deterioration of this relationship. In more active companies, it is up to marketing to sense the new tendencies, which are expressed today in terms of 'experience'. The last frontier of marketing tries to sell experiences - as well as products - inviting sensations and emotions that involve the individual's corporeal perception, sentiments, actions and thoughts, bringing into play aesthetic and ethical values at the moment of consumption and purchase and in all reactions that are created directly or indirectly (with manufacturers, distributors, other customers, other human beings). The behaviour of the consumer, and of human beings generally, is dominated by widespread individualism, but some people assert that a sense of responsibility towards oneself and others can develop from this very individualism (Bauman, 2006).

This establishes a mentality of rights: the individual has rights as a result of his very existence. As a consequence, the power of businesses to influence the behaviour of their interlocutors (consumers, competitors, institutions) is often perceived as an abuse of power; a softer touch is therefore needed, and more incisive involvement based on more articulated stimuli.

Faced with the weakness of social structures, the complexity and fragmentation of reality, a reaction develops which can capitalise new knowledge, starting from diversity, and can be invested in new solidarity and a capacity to understand. A mobilisation develops that is expressed not only in the purchasing behaviour of the individual - who boycotts products of companies considered incorrect - but also through consumer associations that solicit the political powers to issue new laws and to activate procedures to monitor food quality, the fight against pollution, the security of products and of the workplace. In this sense the 'consumerism' movement represents a cultural turnaround. The age-old conflict inside the factory has been joined by conflict between consumers and large brands. Safety, health and 
social fairness become important demands, and for companies that decentralise production at an international level, towards areas characterised by less protection for workers, this contradiction may also become more incisive than that between capital and work (Pepe, 2007).

The stimulus to act to re-establish fair distribution and sustainable development, at least in part, therefore stems from greater consumer accountability, rather than enlightened planners or from companies. Responsible consumers are still a minority, but we must not underestimate their capacity to have a significant influence on the behaviour of other consumers, of institutions or of competitors.

On the other hand, companies reveal an approach that is more in keeping with their nature. They conceive the adoption of new values as part of a model of greater effectiveness and competitiveness on the market, and used as an tool to improve results in terms of profits and positioning.

\section{Contextualisation of Values}

Today, in this debate, the adoption of ethical values appears most topical aspiring to a fairer human condition, sustainable development, containment of risks and uncertainty - but this attitude cannot mortify the attitude of aesthetic values, which remain a fundamental aspect of our culture. Ethical values and aesthetic values are linked, above all in advanced markets where consumers' needs are expressed and customised better. The reference to marketing as a means of highlighting experience reflects the fact that companies are now focusing on these needs, which must however be contextualised.

Ethical and aesthetic values are closely linked to the environment in which they are expressed and experienced. Aesthetics is defined as the subjective sentiment of the harmonious immersion in the environment, while ethics is the subjective sentiment of respect and harmonious interaction with the environment. Ethics enables us to conserve and protect our aesthetic experience, in other words our harmonious coexistence with the Other (made of men and nature). In this sense, the ethics crisis is also the crisis of our co-evolutionary relationship with the Other: it is a crisis in the system of relationships (Longo, 2004).

Since the subjectivity of sensations and principles confers a sense of arbitrariness on the aesthetic and ethical codes, in order to achieve a common definition we should negotiate between the many points of view. Faced with elements of subjective discretionality, there is a need for mediation that makes individual planning incomplete and obliges the individual to turn to other subjects and to cooperate with them.

It is a known fact that the possibility of achieving a balance in relationships reflects two opposing trends: the first is the exercise of the greater power, the other regards cooperation that exploits resources and complementarity for common goals, seeking suitable mediation for the discordant aspects.

Equilibrium based on asymmetries - of power, information and economic resources - currently prevails, but it is clear that the complexity of processes that involve economic entities makes this type of balance increasingly precarious, resulting in shared resources, knowledge and risks, as the fact that companies adopt a variety of forms of national and international cooperation underlines. 


\section{Shared Responsibilities and Global Chains: Research Hypothesis}

The need to cooperate in order to guarantee a consistent supply that is instilled with value, to lower the level of risk and to increase the availability and variety of resources, obliges companies to identify common goals, to rebalance relations between partners, and to create the conditions to improve the results of shared activities. The hypothesis for our research is that possibilities for change can be found in this very interdependence. So our attention is focused on relations within the chain, in particular international relations because they constitute the framework, the skeleton, and the bearing structure of globalisation. In them lies the key to many problems linked to the environmental and social sustainability of development, but also the possibility of identifying some problems linked to this change.

By focusing attention on the international chains and on the nature of relations between the entities that are part of them, we get a better picture of the roles and responsibilities of the individual, and we grasp the sense of how they operate as a system (SA8000 codes of practice also list the requirements of behaviour that is valid not only for individual operators but for the entire circuit they belong to).

Starting from the consumer's new sensitivity, and going back through the chain, the goal is to involve all stages of the economic cycle, so as to conceive a common responsibility in relation to the achievement of economic and non-economic objectives. To this end, we need strong relational structures, investments in communications, innovation, product certification systems and tracking systems along the chain. The cooperative aspect in particular must be transformed into continuous relations and common controlling actions in order to achieve the overall consistency that is presented to the end consumer as a guarantee of a system of values and also as an additional element of value.

\section{Convergence in the Chains of North-South Trade}

In many European countries there is a rapidly growing phenomenon that sees alternative fair trade chains and traditional chains, often dominated by multinationals and large retails groups converge and mutually cross-pollenate. This phenomenon is developing along several alternative lines, creating a multiplicity of circuits of international North-South trade.

Alongside the traditional chains and the fair trade chains a number of hybrid chains are developing, which envisage the sale of fair trade products in traditional retail stores. At the same time, a growing number of traditional operators (industrial and commercial) are managing chains and products certified by fair trade organisms. Then there are the imitation chains, whose operators declare that they respect certain values (ethics, fairness, respect of the environment, etc.) but without requiring certification, for the products or for the chain, but relying solely on the force of their brands and the trust they have won from the clientele.

The spread of these various operating methods shows that (to varying degrees of reliability) it is possible to combine values of economic sustainability with those of environmental and social sustainability, transferring the practices of the alternative trading and ethical finance circuits within processes controlled by operators who are naturally oriented to profit, addressing a broader market. 
The type of chain described above takes shape in them as a source of possible change: i.e. one that on the basis of cooperation made necessary by market reasons, achieves better exploitation of the resources together with greater ethical responsibility and fair distribution.

We can briefly examine the innovations and problems found in the chains that we have analysed.

There can be no doubt that these circuits, more than others, must work with a system logic. When different operators work together, some contents must necessarily be shared, over and above individual motivations and objectives which remain different (linked for some to a social and environmental conscience, and for others motivated above all by the search for a competitive advantage). The relationships are governed by agreed principles, but also by new experimental forms, particularly policies for sales and communications in the premises of mass distribution, although, as we can see in Italy, the presentation of fair trade products or those of non-economic value is still insufficiently incisive and unable to successfully convey the identity of these products.

The importance of the quality of relations between operators, in terms of continuous collaboration, transparency and mutual trust highlights an aspect, that of control, which remains critical in our eyes, both in hybrid chains - where fair trade products are sold through large retail circuits - and in chains that sell certified fair trade products; chains that carry out self-certification are free from any form of external control.

Another critical aspect could be the quantities produced and distributed in response to demand and the size of contracts by large manufacturers or distributors. This obliges small manufacturers in the Southern hemisphere to grow in size through forms of cooperation. The phenomenon is widespread, but the time necessary for this aggregation is not always fast and there are always risks for the weaker producers, who still need to be protected by slow, constant growth rates. What is more, excessively broad supply networks can make it even more difficult to control them.

From the viewpoint of overall strategy and its impact on the market, we can confirm that the values linked to social responsibility represent an innovative component of the product that has a strong potential for development, both for the quantities requested by the market and for the variety of products offered (which all operators, traditional and non-traditional, say they wish to enlarge).

The strategic and economic validity of these chains (Depperu, Todisco, 2007) therefore shows how unjustified criticism of fair trade products is. They are accused of sustaining inefficiency producers, who are incapable of competing on the market with their own strengths and guilty of aggravating the problems of overproduction. The impossibility of competing on the market is often due to an inability to relate rather than to the inadequacy of the product; on the other hand, the presence of numerous small and medium producers in international chains would not be possible without a larger, better informed purchaser to spread the products (Pepe, 2007).

However, the market remains supreme and while recognition by consumers of the distinctive element, i.e. the human validity of the process, remains fundamental, reducing the sense of impotence in the face of the evils of the world and a perception of the risks that may derive from them - recreating for the consumer an experience that is both gratifying and reassuring - it is still important to focus 
attention on product quality and, occasionally, to adapt them to the needs of consumers in developed countries, supplemented by suitable information and communications. The striving for corporate policies that are able to express a correct combination of ethical and aesthetic values (in the sense of a contextualisation of values, as explained earlier) is another of the experiences on which fair trade operators converge today, as well as traditional operators who represent the more innovative part of the phenomenon under examination.

\section{Bibliography}

Alexander A., Nicholls A., Rediscovering Consumer-Producer Involvement: a Network Perspective on Fair Trade Marketing, European Journal of Marketing; vol. 40, n. 11/12, 2006, pp. 1236-1253. http://dx.doi.org/10.1108/03090560610702795

Bauman Z., La vita liquida, Laterza, Bari, 2006.

Bernard D., Il commercio nell'era dello scetticismo, Summit Mondiale del Commercio Alimentare, Barcellona, 18-20 June, 2003.

Caselli L., Progresso scientifico e sviluppo economico in un mondo globalizzato. La sfida etica dell'umanizzazione, Almo Collegio Borromeo, Pavia, Lezioni di etica, n. 1, 2003, p. 6.

Caselli L., Globalizzazione e bene comune. Le ragioni dell'etica e della partecipazione, Edizioni Lavoro, Rome, 2007.

Davies I., Crane A., Ethical Decision Making in Fair Trade Companies, Journal of Business Ethics, Vol. 45, n. 1, 2003, pp. 79-92.

http://dx.doi.org/10.1023/A:1024124629399

Depperu D., Todisco A., Sistemi di creazione di valore nelle filiere equo e solidali, Pepe C. (ed.), Prodotti dal Sud del mondo e mercati avanzati, Franco Angeli, Milan, 2007.

Donalson T., Dunfee W., Business Ethics and Social Contract, Harvard Business School Press, 1998.

Dovolich C. (a cura di), Etica come responsabilità, Nimesis, Milano, 2003.

Jap S. D., Perspectives on Joint Competitive Advantages in Buyer-Seller Relationships, International Journal of Research in Marketing, n. 18, 2001.

http://dx.doi.org/10.1016/S0167-8116(01)00028-3

Longo G. O., Il cervello nudo, Nicolodi Edizioni, 2004.

Latouche S., Come sopravvivere allo sviluppo, Bollati Boringhieri, 2005.

Pepe C. (ed.), Prodotti dal Sud del mondo e mercati avanzati, Franco Angeli, Milan, 2007.

Rusconi G., Dorigatti M., Etica d'impresa, Franco Angeli, Milan, 2005.

Veca S., Le cose della vita, BUR alta fedeltà, Rizzoli, Milan, 2006. 